\title{
perifèria
}

Número 12, junio 2010

www.periferia. name

\section{Repensar Bonpastor: una intervención multidisciplinaria independiente en un barrio afectado por la transformación urbanística}

Stefano Portelli

\author{
Grup de Perifèries Urbanes de I'Institut Català d'Antropologia ${ }^{1}$
}

\begin{abstract}
Resumen
"Repensar Bonpastor - Concurso de ideas para una remodelación participativa y con cero desalojos de un barrio popular de Barcelona", promovido por la Alianza Internacional de Habitantes y organizado por un grupo independiente de técnicos de Barcelona, recibió 45 propuestas desde todo el mundo. El artículo explica como la lucha vecinal de las "casas baratas de Bon Pastor" llegó a entrelazarse con la antropología aplicada, la solidaridad internacional, la historia oral, la arquitectura social, el activismo autogestionario, para intentar construir colectivamente una nueva manera de "hacer ciudad": en que los habitantes sean los verdaderos artífices y protagonistas de las transformaciones, y en que los técnicos (antropólogos en particular) garanticen el respeto hacia los significados y valores que la ciudad representa para sus habitantes.
\end{abstract}

Palabras clave: transformación urbanística, antropología aplicada, arquitectura social, activismo comunitario.

\begin{abstract}
"Repensar Bonpastor - a Competition of ideas for a participative and zero-eviction urban renewal of a popular neighbourhood in Barcelona", promoted by the International Alliance of Inhabitants and organized by an independent group of technicians from Barcelona, received 45 proposals from all over the world. The article explains how the local struggles of the neighbours of the "casas baratas de Bon Pastor" succeeded in gathering applied anthropology, international solidarity, oral history, social architecture, political activism, into a shared attempt to find a new way of "making the city": where inhabitants are the leading actors of the transformations, and technicians (especially anthropologists) guarantee respect towards the meanings and value that the city represents to its inhabitants.
\end{abstract}

Keywords: urban renewal, public anthropology, social architecture, community activism.

\footnotetext{
${ }^{1}$ Enviar correspondencia a: stafe@inventati.org.
} 


\section{perifèria}

Número 12, junio 2010

www. periferia.name

Si hay que buscar un origen para esta historia, el momento inicial sería cuando, en el año 2004, una organización vecinal del barrio de las Casas Baratas de Buen Pastor escribió un correo electrónico a la Plataforma Vecinal contra la Especulación de Barcelona, pidiendo ayuda. El medio utilizado - el correo electrónico - y la propia forma escrita de la comunicación, evidentemente no eran habituales para los integrantes de esta asociación: ancianos obreros de un barrio periférico de Barcelona, con una fuerte conciencia de clase pero con poca práctica política externa a los partidos.

Nos encontrábamos entonces en un momento histórico en que varias instancias incluso externas a la ciudad estaban cuestionando el valor del llamado "modelo Barcelona", que la administración seguía promoviendo a nivel internacional (Raventós 2000; Blanco 2009; Amelang 2007). En la interpretación de muchos pensadores, este "modelo" no representaría más que un instrumento de marketing, a través del cual unas actuaciones urbanísticas neoliberales, impopulares e incluso destructivas del patrimonio histórico y natural, se presentaban como participativas e innovadoras gracias a las retóricas de los partidos de la izquierda (Capel 2005; Delgado 2007; UTE 2004). La Plataforma era en ese momento un espacio de encuentro entre algunos colectivos en lucha contra la especulación inmobiliaria y urbanística ${ }^{2}$, en la época de las transformaciones urbanas anteriores al Forum de las Culturas. Los Avis del Barri de Bon Pastor venían a explicar una historia que muchos - yo formaba parte en ese momento de la Plataforma - encontrábamos difícil de entender. La cuestión principal era que el Patronato Municipal de la Vivienda, entidad dependiente del Ayuntamiento y propietaria de las 784 casas de planta baja que conformaban el barrio, estaba poniendo en marcha un Plan de Remodelación que preveía su derribo integral y la sustitución por bloques de pisos ${ }^{3}$. Finalidad del plan era la de derribar las 784 casas baratas, y ofrecer a cada familia

\footnotetext{
2 Formaban parte de la Plataforma en ese momento: la Coordinadora contra l'Especulació del Raval, la Plataforma d'Afectats pel 22@, el Col-lectiu del Forat de la Vergonya, Arquitectes Sense Fronteres Catalunya, y esporàdicamente otras entidades como el Centre Social de Sants, y la Plataforma Veïnal de Trinitat Vella.

${ }^{3}$ Modificació al Pla General Metropolità (MPGM) al Polígon de Cases Barates de Bon Pastor. Ajuntament de Barcelona, Secció d'Urbanisme, 20-3-2001.
} 


\section{perifèria}

Número 12, junio 2010

www. periferia. name

titular de una casa la posibilidad de acceder a uno de los nuevos pisos construidos sobre el terreno del barrio. Esta actuación tenía el apoyo incondicional de la Asociación de Vecinos del barrio y de la misma Federación de Asociaciones de Vecinos de Barcelona (FAVB); pero, según los Avis del Barri, además de representar el fin del estilo habitativo peculiar del barrio, también implicaba la pérdida de derechos de los inquilinos, y el riesgo para muchas familias, a la larga, de ser expulsadas del barrio en el cual habían vivido durante generaciones. El nombre escogido por la organización, que había nacido en 2003 precisamente para canalizar la disidencia vecinal a esta transformación, implicaba precisamente esta voluntad de defender la permanencia en el barrio de sus "abuelos", es decir, los ancianos hijos de los primeros inquilinos de las casas, sus fundadores, que llegaron a Barcelona desde Murcia, Andalucía o del interior de Cataluña, poco antes de la construcción de las casas baratas, en el año 1929.

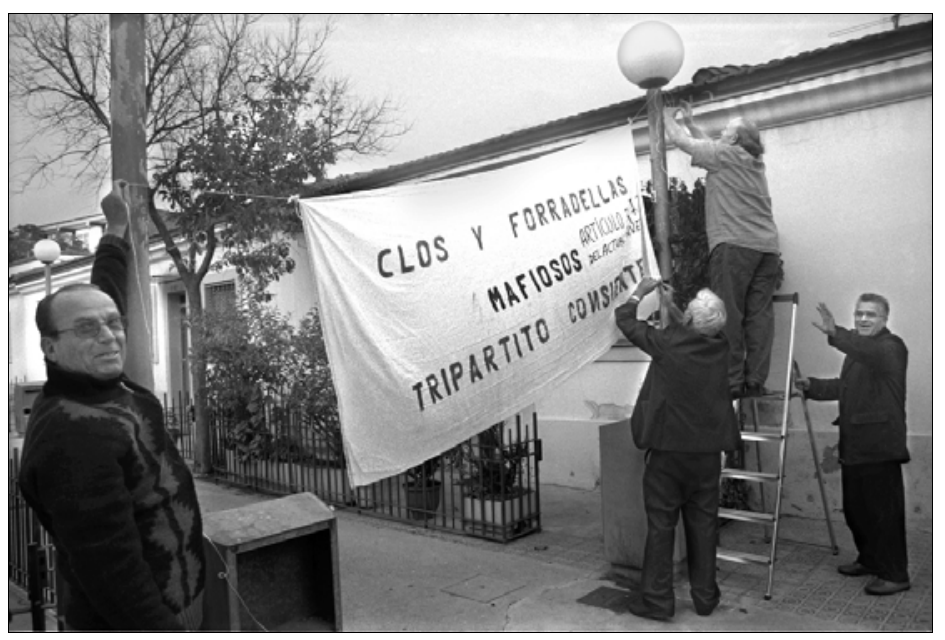

\section{MAGEN 1}

Los "Avis del Barri" cuelgan un cartel en la calle Ager (hoy derribada). Foto Carola Pagani, 2004.

Los Avis del Barri habían puesto en marcha una serie de recursos legales, fatigosamente financiados a través de recolectas y rifas vecinales, en contra del Plan de remodelación; sus reivindicaciones eran sistemáticamente silenciadas por los medios de comunicación y dejadas de lado por las instituciones. Incluso a nosotros, a veces, nos parecían poco claras: iban de la crítica en contra del derribo del barrio, a la demanda de mejores condiciones de realojo para los inquilinos más 


\section{perifèria}

Número 12, junio 2010

www. periferia. name

antiguos, a la protesta sobre detalles formales del Plan que nos parecían de escasa importancia. No nos extrañaba el papel que supuestamente estaría jugando la Asociación de Vecinos, parecido al que tuvieron análogas asociaciones en otros barrios en transformación ${ }^{4}$; pero al mismo tiempo nos encontrábamos con demandas a las cuales no sabíamos cómo responder, por ejemplo cuando se nos pidió "okupar" una casa que el Patronato había cerrado, para forzar su reasignación y evitar el derribo. Como Plataforma decidimos ofrecer al barrio una herramienta que pudiera hacer luz sobre lo que nos parecía el elemento central: la opinión de los habitantes de las "casas baratas" acerca de su demolición.

Propusimos entonces una encuesta independiente sobre las opiniones de los vecinos, en la cual me involucré como antropólogo con experiencia en diagnósticos comunitarios $^{5}$. En los meses de julio y agosto del 2004 realizamos 100 entrevistas, por un total de más de 20 horas de grabación en audio, entre los habitantes de las primeras 145 casas afectadas del barrio ${ }^{6}$. En el caso de reconocer la existencia de un problema en el barrio de Bon Pastor, nos hubiéramos encontrado delante de una aplicación particularmente perversa del "modelo Barcelona": por el número de habitantes afectados, por la titularidad pública de todo el conjunto, por la retórica de la participación empleada, y, sobre todo, por la historia de exclusión social de la cual fue protagonista este barrio durante sus ochenta años de existencia.

Efectivamente, una vez transcrita la totalidad de las entrevistas y elaboradas las conclusiones ${ }^{7}$, nos resultó claro que, para la mayoría de los habitantes de las casas baratas, la transformación urbanística representaba un grave problema, tal como nos habían señalado los Avis del Barri.

\footnotetext{
${ }^{4}$ Un caso entre muchos: el de la Asociación de Vecinos del Raval. Un interesante trabajo investigativo sobre el giro conservacionista que dieron muchas Asociaciones de Vecinos es el que realiza el colectivo de historiadores Pràxis de la Universitat Autònoma de Barcelona. Sobre el caso de la Taula del Raval es imprescindible De nens (J oaquim J ordà, 2003).

${ }^{5}$ En los años 1999-2000 había trabajado en el barrio Memorial Sandino de Managua, Nicaragua, con la ONG “Movimondo" de Roma. En 2000-2001 había trabajado sobre el mapa social del territorio del V Municipio de Roma, para el proyecto Sostegno al Contesto.

6 "La Plataforma contra l'Especulació vol enqüestar el veïnal de les Cases Barates", Ciutat Nord - Sant Andreu, juliol-agost 2004,

7 El informe, consultable en «ttp://barcelona.indymedia.org/newswire/display_any/173299> se presentó como prueba técnica de parte en uno de los Contenciosos Administrativos interpuestos por los Avis del Barri.
} 


\section{perifèria}

Número 12, junio 2010

www. periferia. name

[...] los ancianos como los jóvenes perciben el Plan como una imposición desde arriba con la cual no queda más remedio que conformarse, tanto para los que ganan como para los que pierden. Esta percepción [...] contrasta enormemente con la retórica del Ayuntamiento y de la Asociación de Vecinos, que promueven el Plan de Remodelación como una conquista del movimiento vecinal.

Hay unas cuantas entrevistas que nos impresionaron especialmente porque las personas entrevistadas, aunque dicen estar a favor del Plan, también añaden que no había posibilidad de oponerse, y dicen que aunque no les guste tendrán que aceptarlo igualmente [...] y resaltan que hay una contradicción fuerte entre retórica y realidad.

[...] Especialmente chocante resulta por ejemplo la declaración del alcalde Joan Clos en la introducción del último libro de historia del Patronato, De les cases barates als grans polígons: afirma que la política del Ayuntamiento es "potenciar el alquiler e impulsar la rehabilitación"8, cuando el Plan de Remodelación de Bon Pastor potencia la compra de viviendas, el derribo de las casas antiguas y la construcción de nuevos bloques.

\section{EI pasado y sus fantasmas}

Las 784 Casas Baratas de Bon Pastor forman parte de los cuatro polígonos que el Ayuntamiento de Barcelona edificó en 1929, en terrenos muy alejados del centro de la ciudad, para resolver el problema de la "vivienda para clases obreras" ${ }^{9}$. Esta problemática entró a formar parte de las agendas de los principales gobiernos municipales de los países industrializados entre finales del siglo XIX y principios de XX. En Barcelona, la Ley de Casas Baratas, aprobada por el gobierno español en el 1911, se aplicó con ocasión de la Exposición Universal de 1929, con la construcción

\footnotetext{
8 "Aquesta llarga tradició és las que ens permet llançar noves idees i propostes destinades a potenciar l'habitatge de lloguer, impulsar la rehabilitació i ampliar el nombre d'habitatges existents a Barcelona". J oan Clos, introducció a De les cases barates als grans polígons, Ajuntament 2003.

${ }^{9}$ Esta reconstrucción histórica se basa en una investigación en la cual participé durante el año 2009, dentro del marco del Memorial Democràtic de Catalunya, con el título "Represalias y resistencias en las casas baratas de Bon Pastor".
} 


\section{perifèria}

Número 12, junio 2010

www. periferia. name

de cuatro conjuntos de Casas Baratas por parte del recién creado Patronato Municipal de la Vivienda (PMH 1999) ${ }^{10}$. Dos de estos conjuntos se edificaron incluso en terrenos inundables - y por esta razón, baratos - que no pertenecían al municipio de Barcelona, sino al de Santa Coloma de Gramenet (Ontiveros 1992; Fabre y Huertas 1976:80-83; Checa Artasu 2002). Este pequeño municipio rural, a la orilla del río Besós, vio con esta actuación doblar su población, sin recibir ni ayudas económicas, ni siquiera información, por parte del Ayuntamiento de Barcelona ${ }^{11}$. El más grande de los dos barrios, que luego será Bon Pastor, entonces se llamaba "segundo grupo de casas baratas" o "Milans del Bosch". Este polígono se vio sometido a una doble marginación, ya que era difícil su acceso desde Barcelona, a través de los campos, y también desde Santa Coloma, de la que estaba separado por el río Besós.

A la marginación geográfica se le sumó la marginación cultural: la procedencia étnica de las familias de las casas baratas - en gran mayoría inmigrantes del sur de España (Márquez Rodríguez 2000) - marcaba una distancia incluso lingüística con respeto a los núcleos de población más cercanos, habitados principalmente por catalanohablantes. Pero el factor que caracterizó el barrio desde sus inicios fue sin duda el económico. Los habitantes de las casas, en su mayoría obreros y obreras de las fábricas metalúrgicas y textiles de los distritos de Sant Andreu y Sant Martí, fueron fuertemente golpeados por la crisis de 1929, que los dejó aislados, en medio del campo y $\sin$ recursos ${ }^{12}$. No había ni servicios sanitarios para hacer frente a las epidemias (por ejemplo, a la tuberculosis), ni un mercado para garantizar una alimentación equilibrada para la población. Sin embargo las Casas Baratas tenían un cuartel de la Guardia Civil y una parroquia, en funcionamiento desde el momento de su fundación. Del colegio, también edificado por el Patronato, tenía que haberse encargado el municipio de Santa Coloma, que no disponía ni de fondos

\footnotetext{
${ }^{10}$ Entonces Instituto Nacional de la Habitación.

${ }^{11}$ Del periódico Las Noticias, octubre 1932: “[...] unos señores de Barcelona vinieron aquí y, sin solicitar ninguna clase de permiso, se apoderaron del terreno que les convino y edificaron los grupos de casas baratas a los que 'nos importaron' una serie de familias, la mayor parte de ellas indeseables, procedentes de Murcia y otros lugares de España, pobres y llenos de lacras morales". Cit. en Gallardo 2000: 175 .

${ }^{12}$ El Diluvio, 18-1-1931: "Más de 3500 habitantes viviendo en peores condiciones que en el Rif' (cit. in Gallardo, 2000: 173)
} 


\section{perifèria}

Número 12, junio 2010

www. periferia. name

suficientes, ni de voluntad política, para ponerlo en marcha (Gallardo, 2000:172175).

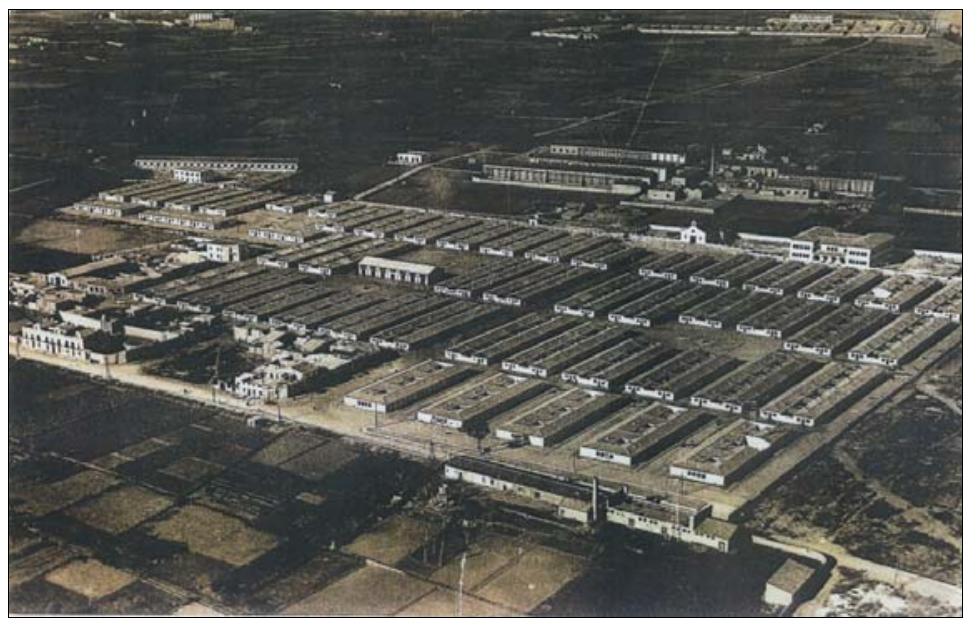

\section{MAGEN 2}

El "segundo grupo" de Casas Baratas, hoy Bon Pastor.

Instituto de la Vivienda, 1931.

La misma estructura ortogonal del barrio de Casas Baratas hace reflexionar sobre la intencionalidad que presidió a su construcción. Más que ofrecer viviendas para obreros, posiblemente, el objetivo del Ayuntamiento fue el de desprenderse de elementos potencialmente peligrosos, tal como se vino haciendo en muchas metrópolis europeas en la misma época. Como evidenció Pasolini a propósito de las contemporáneas borgate de Roma, el urbanismo que presidía a este tipo de actuaciones podríamos definirlo concentracionario ${ }^{13}$.

A esta intencionalidad se contraponen las estrategias de resistencia que desplegaron los habitantes de las casas baratas a partir del momento mismo de su fundación. Parte integrante del que se definió cinturón rojo y negro de Barcelona (Oyón 2005), el barrio se adhirió de forma generalizada al anarcosindicalismo: de los habitantes de las Casas Baratas se decía que eran todos "murcianos y de la FAl" (Gallardo Romero, 2000). Si durante la República estos habitantes "pobres y plenos de lacras morales"14 destacaron por su alto nivel de autoorganización (por ejemplo a través de una Cooperativa de consumo, que se inauguró en el 1929, y de la

\footnotetext{
13 "Construidas por los fascistas, y consagradas por los cristiano-demócratas, las borgate son verdaderos campos de concentración". (Pasolini, 1992:46).

${ }^{14}$ Ver nota 12.
} 


\section{perifèria}

Número 12, junio 2010

www. periferia. name

masiva huelga de alquileres en contra del Patronato), este compromiso durante la Guerra Civil llegó a su punto álgido: varias columnas de milicianos partieron para el frente desde las casas baratas para luchar contra el fascismo. El barrio fue bombardeado por la aviación italiana, y sufrió durísimas represalias con la entrada de la dictadura. Algunos habitantes de las casas recuerdan los camiones que salían desde el barrio, cargados de jóvenes y de familias enteras, huyendo hacia Francia por temor a las matanzas de los "nacionales".

Los años que siguieron a la Guerra Civil conformaron el peor de los escenarios para la recuperación de las heridas psíquicas y morales de la guerra. Recientes estudios de psiquiatras y psicólogos sobre la transmisión intergeneracional del trauma bélico, nos han mostrado con claridad que, todo y haber acontecido más de medio siglo atrás, los eventos de los años 30 y 40 son imprescindibles para entender "el enrarecimiento de la convivencia" en la España de hoy (Miñarro y Morandi 2009; Ruíz Vargas 2006).

Porque aquellas víctimas derrotadas, a diferencia de los vencedores, que usaron e incluso abusaron de su derecho a llorar y honrar a sus 'caídos', se vieron obligadas a tragar sus lágrimas y su dolor, a ocultar o renegar de sus ideas, a sentir vergüenza de su condición ideológica, a autoimponerse el más férreo de los silencios; en definitiva, a ahogar a su propia memoria, y con ella toda posibilidad de elaboración, duelo y superación de los horrores de la guerra (Ruíz Vargas 2006: 301).

Las dimensiones del horror vivido por los vencidos, la magnitud del "exterminio del adversario político" (Espinosa 2005) puesto en marcha por el régimen franquista, siguen considerándose inferiores a lo que fueron, a pesar de las recientes leyes nacionales sobre memoria histórica ${ }^{15}$. El franquismo sigue gozando de cierto respeto, frente a las dictaduras públicamente más despreciadas, el nazismo y el estalinismo por ejemplo: como si sólo se hubiera tratado de una época de austeridad y autarquía. De la dictadura en Bon Pastor se suelen subrayar los elementos del hambre y el aislamiento, y perder de vista otros quizás más

\footnotetext{
${ }^{15}$ La referencia es a la Ley 52/2007, conocida como Ley de Memoria Histórica.
} 


\section{perifèria}

Número 12, junio 2010

www. periferia. name

determinantes: el silencio y el terror. Un dictador que al llegar al poder declaró su voluntad de "exterminar a media España" para erradicar el marxismo ${ }^{16}$, difícilmente hubiera mantenido un barrio como las casas baratas, rojo al $100 \%$, simplemente en una situación de aislamiento. Sólo un trabajo intensivo, y urgente, que implique un uso sistemático de la historia oral, podrá ayudarnos a aclarar la dimensión del trauma vivido por los habitantes de las casas baratas durante las décadas de cotidianidad bajo el franquismo ${ }^{17}$. La memoria histórica, y la de la Guerra Civil en particular, es un elemento que forma parte del presente del barrio, no de su pasado. Ningún estudio sobre los conflictos generados por el Plan de Remodelación en las casas baratas, puede darse, si no toma en cuenta este hecho ${ }^{18}$.

\section{Un polígono de símbolos}

Toda esta historia, desde los años de la Guerra y dictadura, junto con los que los precedieron (que para cada familia representaron un recorrido migratorio diferente) y con los que los siguieron (la época de la transición, de la heroína, y del imaginario "quinqui" de los ochenta), más que un contexto previo, representa un conjunto de símbolos, que los habitantes utilizan como lenguaje para interpretar y actuar en el presente. Estos elementos se ofrecen para múltiples interpretaciones, diferentes según los grupos y los momentos históricos de cada componente de la comunidad, organizados en aglomerados complejos, a veces ocultos, a veces menos ${ }^{19}$.

Por ejemplo, un elemento clave es el aislamiento de las casas baratas respeto a la ciudad. Muchos habitantes jóvenes de las casas siguen sin casi salir del barrio, y casándose entre ellos. Aunque el barrio estuviera separado de la ciudad antes por campos, ahora por fábricas, el aislamiento de las casas se reproduce en el tiempo.

${ }^{16}$ Cito aquí la famosa entrevista de Jay Allen con el dictador en el Chicago Daily Tribune, 28 y 29 de julio de 1936.

${ }^{17}$ Un trabajo de este tipo empezó a realizarse con una financiación del Memorial Democràtic de Catalunya bajo el título "Represàlies i resistències a les cases barates de Bon Pastor", cit., nota 10.

${ }^{18}$ El stage de trabajo de campo realizado por estudiantes de la UB en 2005, coordinados por Manuel Delgado, tituló sus conclusiones "Memoria y conflicto"; el proyecto de investigación sobre Casas Baratas financiado por el Inventario del Patrimonio Etnológico de Catalunya que empezó en 2009, se llama "Lucha social y memoria colectiva en las casas baratas de Barcelona".

19 "Todas las contradicciones de la vida social humana [...] se condensan y se unifican en una representación única, los símbolos dominantes. El objetivo del análisis es romper este amalgama en sus componentes primarios" (Turner, 1967:44). 


\section{perifèria}

Número 12, junio 2010

\section{www.periferia.name}

Pero sus significados son múltiples y complejos, y pueden variar con los años. El aislamiento significa por un lado el abandono institucional, "nadie se ha preocupado hasta ahora 20 "; por el otro, es el elemento que ha permitido que se formara una comunidad bien definida y cohesionada: un "pueblo en medio de la ciudad", "una gran familia aquí". Que el barrio llegue a la ciudad ${ }^{21}$ no necesariamente es positivo: la ciudad quedaba lejos, con su modernidad, pero también con su control social, sus leyes, sus prejuicios. Además, aunque vivieran apartados, los habitantes de las casas baratas han sido, y siguen siendo, las obreras y los obreros de Sant Andreu y de Poblenou, los albañíles que han construido el metro, los vendedores de la Boquería... Sobre la relación del barrio con la ciudad existe una negociación constante, que parte de las interpretaciones de la historia, pero cuya finalidad es política, y dirigida hacia el presente.

El mismo nombre de "Bon Pastor" es una amalgama compleja. Fue Mossén Joan Cortinas $^{22}$, párroco que desarrolló una importante labor social en el barrio durante la postguerra, quien lo bautizó así, con la intención de rescatar a sus habitantes de la marginación social implícita en la expresión "casas baratas". Pero la marginación social, en el lenguaje de la dictadura, también incluía la disidencia política: el barrio que así se bautizó, apenas nueve años antes, había protagonizado el linchamiento del párroco de la iglesia del Bon Pastor $^{23}$. Este nombre sigue vehiculando la suplantación de la identidad reivindicativa que había sido propia de las casas baratas; mientras que la misma expresión "casas baratas" no deja de contener una referencia de desprestigio, al escaso valor económico de las viviendas. “¡De baratas nada!" o "a nosotros no nos salió barata" insisten muchos inquilinos antiguos, al resaltar la cantidad de dinero que las propias familias tuvieron que invertir para mantener las casas en buen estado. Expresiones como "las llamaron baratas

\footnotetext{
20 Las frases entre comillas son extraídas de entrevistas realizadas en las Casas Baratas entre 2004 y 2010. La problemática del barrio ha hecho necesaria su anonimización.

21 "Bon Pastor ya se siente de Barcelona", se ha escrito en ocasión de la inauguración de la estación del metro. Público, 26-4-2010.

22 "Sacerdote postconciliar antes del Concilio" lo definieron Fabre y Huertas Clavería (1976: 153). Cortinas, 1992.

23 Se trata de Mossén Carles Ballart, que a diferencia del sacerdote anterior Mn.Pujalt, era muy impopular entre los vecinos de las Casas Baratas (Cortinas 1992: 99; Gallardo 2000:172).
} 


\section{perifèria}

Número 12, junio 2010

www. periferia. name

porque las hicieron con el material sobrante de la Exposición Universal" condensan un sinfín de interpretaciones de la historia, entre los cuales la idea del barrio como vertedero, donde echar "todo lo que sobra". Se trasfiere la calidad de "sobrante" de la población, "indeseable", de 1929, a los materiales con que supuestamente se construyeron las casas. Naturalmente, los materiales sobrantes, que el Ayuntamiento había adquirido para construir la Expo, no tienen porqué ser de mala calidad; pero la mala calidad es una característica que impregna el barrio entero, y transita impalpable desde los habitantes hacia sus habitaciones, legitimando su derribo.

La versión oficial de la historia es que las casas se hicieron "para alojar a los barraquistas de Montjuïc", es decir para despejar la montaña donde se celebraría la Exposición del 1929. Pero la construcción de casas baratas para obreros era un asunto anterior al realojo de barraquistas; además, la mayoría de habitantes de las casas no proceden de Montjuïc, sino que vivían realquilados en los barrios del centro de Barcelona, o en Poblenou, o en Sant Andreu. Si ha habido barraquismo, en alguna de las historias familiares, ha sido como etapa de un proceso migratorio. Caracterizar el barrio como población de ex-barraquistas o como obreros inmigrantes, marca una diferencia: "barracas" es una palabra densa, en el significado geertziano del término, porque vincula indisolublemente, incluso léxicamente, el barrio de hoy con el problema de la "infravivienda en Catalunya" ${ }^{24}$.

De la misma manera, el derribo de las Casas Baratas también viene a asumir significados contrapuestos. La palabra "remodelación", explícitamente ambigua, condensa dos simbolismos: a la vez - como mantiene la Asociación de Vecinos representa la necesaria y esperada modernización que rescate al barrio de un pasado de miseria y privaciones, acompañando a sus habitantes hacia el nuevo milenio; por otro lado - como sostienen los Avis del Barri - representa la persistencia de la "urbanística del desprecio" (Brunello, 1996) a través de la cual la burguesía de la ciudad sigue aprovechándose de los terrenos y de las viviendas de

\footnotetext{
${ }^{24}$ También por el papel de "anticiudad" que caracteriza la montaña de Montjuïc: "una mena de limbe [al qual] s'aboca tot allò que es considera [...] aliè, perifèric o residual en la representació de la pròpia ciutat". Delgado 2003: 95.
} 


\section{perifèria}

Número 12, junio 2010

www. periferia. name

los más humildes. Expulsados de sus tierras por el empobrecimiento rural del sur, luego desalojados de los barrios de Barcelona y de Montjuïc a principios de siglo, marginados en las afueras de la ciudad, de nuevo amenazados porque sus terrenos, afectados por la estación del Alta Velocidad de La Sagrera, han empezado a tener demasiado valor. Una historia de las “malas familias de Barcelona 25 " podría quizás escribirse aquí, resaltando esta percepción que, en el curso de las décadas, las necesidades de espacio de las élites ciudadanas siempre recayeron sobre los descendientes de las mismas familias.

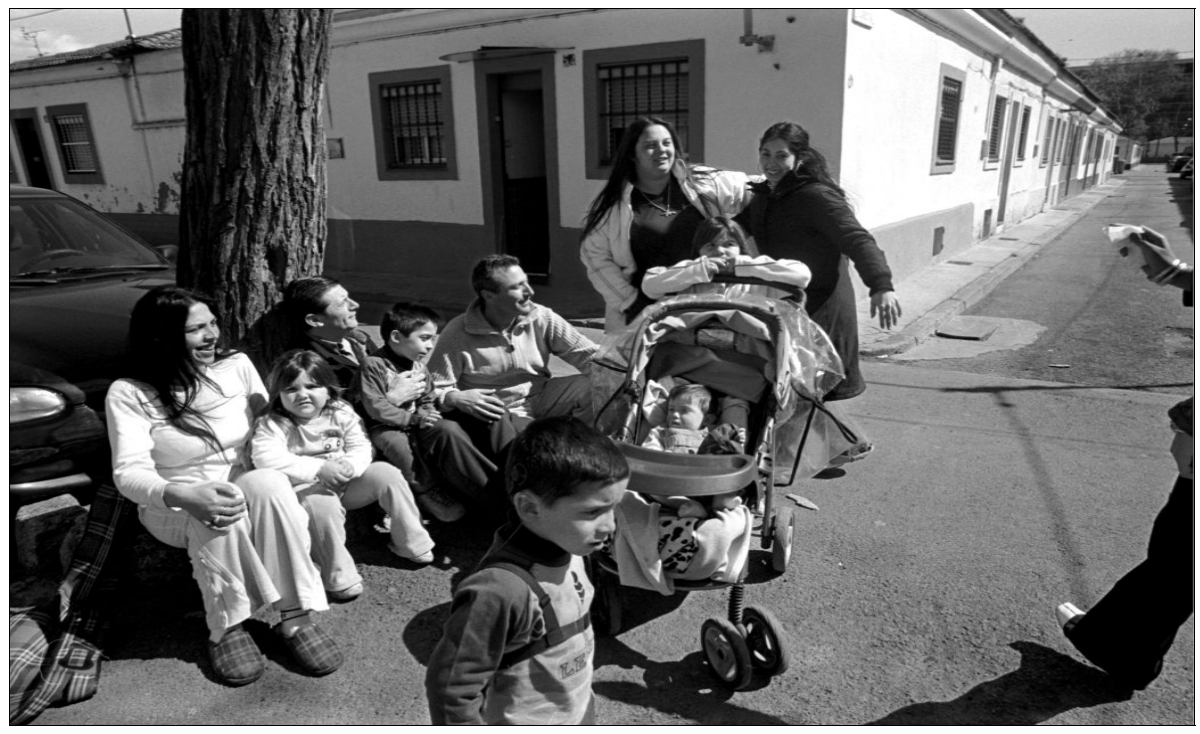

I MAGEN 3: Vida en la calle en el barrio de Casas Baratas. Foto Carola Pagani, 2004.

\section{Las personas y las piedras}

Comprender este entramado de símbolos opuestos, y de interpretaciones contrarias, podría llevarnos a un relativismo paralizante, que nos impediría entrar

\footnotetext{
25 La paráfrasis hace referencia al conocido estudio de MacDonogh (1986) The Good Families of Barcelona. Princeton: Princeton University Press.
} 


\section{perifèria}

Número 12, junio 2010

\section{www. periferia. name}

en escena con una posición definida ${ }^{26}$. Pero no hay que olvidar que el origen de esta historia es una demanda de ayuda por parte de un colectivo de habitantes del barrio, a la cual responder con una contribución que no puede ser sólo teórica. En el contexto de Bon Pastor, de urgencia y conflicto, no puede darse una presencia que no intente aportar elementos hacia la solución de ese conflicto. Así que la antropología debe hacerse práctica, a pesar de todas las reticencias.

El Plan de Remodelación, aprobado después de un polémico referéndum en 2003, polarizó los habitantes de las casas baratas entre "favorables" y "contrarios". Por un lado están las familias de habitantes más antiguos del barrio, entre los cuales los Avis del Barri recogieron en su momento el apoyo de 200 núcleos familiares, que mantienen sus contratos indefinidos, de subrogación forzosa, con alquileres muy reducidos y una larga trayectoria familiar en las $\operatorname{casas}^{27}$. Por el otro están las familias que apoyan a la Asociación, y que consideran estas protestas como poco más que expresiones de nostalgia por parte de unos ancianos, que impiden que las familias que lo necesitan sean realojadas a los nuevos pisos ${ }^{28}$.

El problema, como ya se ha dado en otros procesos de transformación urbana en Barcelona, no es el de priorizar "las personas o las piedras", es decir, las casas o sus habitantes. Cuando las personas que critican la demolición son tildadas de nostálgicas ${ }^{29}$, probablemente se está simplificando la relación que los habitantes tienen con las casas baratas: "Aquí ha nacido mi padre, he nacido yo, me casé y tuve hijos; tuve a mi hija, se casó, ahora ella tiene hijos: han sido cinco generaciones en la misma casa". No es casual que cuando se habla de las casas, los

\footnotetext{
${ }^{26}$ Es la posición que hizo propia la presidenta de una de las asociaciones que habían dado su apoyo a la Remodelación; como antropóloga, nos dijo no estar interesada en la encuesta vecinal, porque "lo que dice la gente es relativo", por lo tanto no podía darse crédito a las opiniones recogidas. De esta manera, se valida de hecho el resultado de un referéndum en el cual los vecinos sólo podían expresar un "sí" o un "no", sin la información suficiente ni la potestad vinculante necesaria para que el resultado no fuera "relativo".

27 Para muchas de estas familias "las casas ya tendrían que ser nuestras", por el esfuerzo y el dinero gastado en ellas, frente a la falta de compromiso del Patronato.

28 Muchas de las familias "favorables" han sido realojadas por el Patronato en el barrio durante los últimos veinte años: por lo general, recibieron viviendas en malas condiciones y con altos alquileres, con la promesa de ser trasladados pronto hacia un piso nuevo.

29 "Les combattants de la nostalgie, les chevaliers du passé" se definía a quienes en los 60 criticaban los derribos en el centro de Paris (Fermigier 1991).
} 


\section{perifèria}

Número 12, junio 2010

www. periferia. name

eventos que se recuerdan en ellas son nacimientos y muertes: "aquí ha muerto el papa" o "aquí ha nacido mi abuela". Es difícil evaluar el impacto psicológico del derribo de unas viviendas que por tantos años han representado - y en algunos casos siguen representando - el único elemento de estabilidad, entre las persecuciones políticas, la precariedad laboral, las adicciones, la violencia doméstica.

Muchos inquilinos, muy a menudo, hablan de las Casas Baratas como si fueran miembros de sus familias. "Han matado a mi casita" escribió una habitante joven después del derribo de su casa. Durante el último año, dos ancianos habitantes de la calle Bellmunt murieron, ambos justo dos meses después de haber dejado la vivienda. "Fíjate tú lo que han durado, desde que dejaron la casa", fue uno de los comentarios más oídos. "Más de un anciano no aguantará, cuando tenga que irse al piso", grabamos ya en 2004. El derribo del barrio, personificación de todas las relaciones entre sus habitantes, es una muerte en sí, aunque la propaganda insista con expresiones del tipo "Bon Pastor, un barri amb futur" (un barrio con futuro). Una foto del reportero J oan Alvado, publicada en el diario La Directa, retrata a dos inquilinos a punto de perder su vivienda, alrededor de una placa de la calle Granadella, sobre la cual habían escrito, en lápiz: “Nací el 1-1-1929. Comienzan ha (sic) matarme, el 14-5-2007".

La conformación física del barrio, además, ha favorecido el mantenimiento de estructuras sociales que probablemente no sobrevivirán al derribo. De pequeñas dimensiones y cercanas las unas a las otras, las Casas Baratas permiten un tipo de relaciones "en la puerta" - "hablamos en la puerta", "nos vemos en la puerta de tu casa" - que son de mayor proximidad respecto a las que se desarrollan en el espacio público (se puede estar en pijama, o en zapatillas), pero de menor proximidad respeto a las que se desarrollan en el espacio privado. Esta zona de transición, entre el espacio privado del comedor y de las habitaciones, y el espacio público de la calle y de las plazas, contribuye en aliviar la soledad de los ancianos (muchos de los cuales no están acostumbrados a recibir visitas dentro de la casa, pero desarrollan la mayoría de sus relaciones "en la puerta") y permite una vigilancia compartida de los niños. Además, ya que de esta manera los habitantes 


\section{perifèria}

Número 12, junio 2010

www. periferia. name

de las Casas Baratas están constantemente expuestos a las miradas y comentarios de los vecinos, todo el barrio funciona como una gran plaza de un pueblo, en la cual todos se conocen y tienen que relacionarse: familiares, amigos, vecinos, conocidos, y enemigos ${ }^{30}$.

"Antes, cuando vivíamos en las casas - nos cuenta un inquilino realojado en los nuevos pisos - si tenías un problema con alguien, sabías que tarde o temprano llegaría el momento en que lo pillarías en la calle". Raras veces, en los seis años de trabajo de campo en Bon Pastor, he visto que los problemas entre vecinos hayan acabado con violencia. Incluso un día en que dos miembros de los bandos enfrentados - uno de la Asociación de Vecinos, otro de los Avis del Barri - llegaron a gritarse en la calle, noté que nadie de los presentes se preocupó de separar a los enfrentados: de hecho, mientras las acusaciones se hacían siempre más personales, uno de los dos recordó al otro que tenían un amigo común, y que sólo por esta razón no iba a llegar a las manos. El entramado de relaciones, familiares, vecinales, laborales, que vincula a todos los habitantes de las casas baratas, es un recurso comunitario al cual acogerse para evitar de usar la violencia. Incluso entre los menores, comparativamente con otros barrios de Barcelona y de los alrededores $^{31}$, he podido observar como a menudo estructuras del tipo "como tú llames a tu padre yo llamo a mi hermano que le va a pegar" han evitado la insurgencia de conflictos, recorriendo a estas redes de las cuales forman parte también los niños, sin la necesidad de la intervención de un adulto ${ }^{32}$.

Uno de los elementos potencialmente generador de conflictos, entre los habitantes, es la diferencia entre gitanos y no gitanos (payos). A finales de los años 80 , con el derribo del asentamiento de La Perona, muchas familias gitanas fueron realojadas en las casas baratas. La mayoría de estas familias, por lo general muy numerosas,

\footnotetext{
${ }^{30}$ Herzfeld (2009:77), sobre el barrio de Monti en Roma: "residents' needs include fraternal love, the desire for relationships, but also envy, jealousy".

31 Durante los años 2003-2004 tuve la oportunidad de trabajar en el colegio público de las casas baratas. En 2006 pude comparar las observaciones que allí realicé con la realidad de otro colegio público de la zona, el Barón de Viver, cuyos niños procedían de familias realojadas en los años 80 de las Casas Baratas a pisos de nueva construcción.

32 El deporte más popular del barrio, la competición de canto de pájaros, parece metáfora de esta costumbre: los jilgueros y los canarios, cuando se le abren las jaulas se desahogan a través del canto, que determina quién gana y quién pierde, sin necesidad de derramar sangre.
} 


\section{perifèria}

Número 12, junio 2010

www. periferia. name

se encontraron con peores casas y con alquileres mucho más altos de los que pagaban las familias "históricas" del barrio. Esta diferencia, junto con otras (como el distinto uso del espacio público que hacían las familias gitanas ${ }^{33}$ y payas), en más de una ocasión generaron problemas de convivencia entre las dos comunidades. Otra vez, la estructura del barrio ayudó en absorber los potenciales conflictos.

Por ejemplo, en la dramática época de los años 80, cuando todos los jóvenes del barrio, tanto gitanos como payos, se encontraron con la difusión mortífera de la heroína, la proximidad de las familias en vez de generar polarización generó mestizaje. Una generación de jóvenes nacidos en el barrio entre los 60 y los 70 compartieron las escuelas y los espacios de encuentro; hasta construir un lenguaje y una cultura juvenil que atravesó la diferencia étnica, y que llegó hasta la época actual. Hoy en el barrio hay parejas mixtas, familias vinculadas por bodas, una educación de los niños bastante parecida, incluso una estética común. A menudo, a los integrantes de este "tercera cultura" mestiza, se le llama garrulos, definición que ellos mismos utilizan sin intención despectiva. Muchos garrulos en el barrio desarrollan la función de mediadores naturales en los conflictos que puedan surgir entre las dos comunidades.

En tiempos recientes esta proximidad se está viendo separada de nuevo, por ejemplo a través de la polarización escolar. En los últimos años, la escuela pública del barrio se ha caracterizado por una fuerte presencia gitana, así que la mayoría de padres payos envían a sus hijos a la escuela concertada, o incluso fuera del barrio $^{34}$. El racismo y la xenofobia nunca han faltado entre los habitantes de las Casas Baratas; pero la proximidad habitativa, y la estructura horizontal del barrio, han ofrecido un terreno relacional común que ha evitado que brotara la violencia.

La culminación de este conjunto de etnotécnicas, para la resolución de conflictos entre vecinos, es la fiesta de Sant Joan, el 23 de junio. En la tradición catalana, en la revetlla se encienden hogueras, para celebrar la llegada del verano. En las casas

\footnotetext{
33 San Román, 1997.

34 La Vanguardia, 31/5/2007.
} 


\section{perifèria}

Número 12, junio 2010

www. periferia. name

baratas esta fiesta, hasta años muy recientes, todavía mantenía su función terapéutica: "todos los problemas que tenías, esta noche los solucionabas alrededor del fuego". El ritual de las hogueras, que en la ciudad contemporánea ha perdido casi todo su significado, en un barrio que aún mantiene una fuerte estructura comunitaria, sigue manteniendo su función catártica. Cada año, "todos volvíamos a empezar de cero" comiendo y bebiendo alrededor de la hoguera, olvidando los rencores y las tensiones acumuladas.

En 2005, con las ordenanzas cívicas del Ayuntamiento de Barcelona, se reglamentaron las hogueras y se prohibió el consumo de alcohol en la calle, ilegalizando de hecho la celebración de la fiesta de San Juan. Las hogueras en el barrio se apagaron en 2007 , en los solares vacíos resultantes del derribo de las primeras casas baratas; cuatro meses antes de la llegada de los antidisturbios de la Guardia Urbana, que celebraron los primeros desahucios.

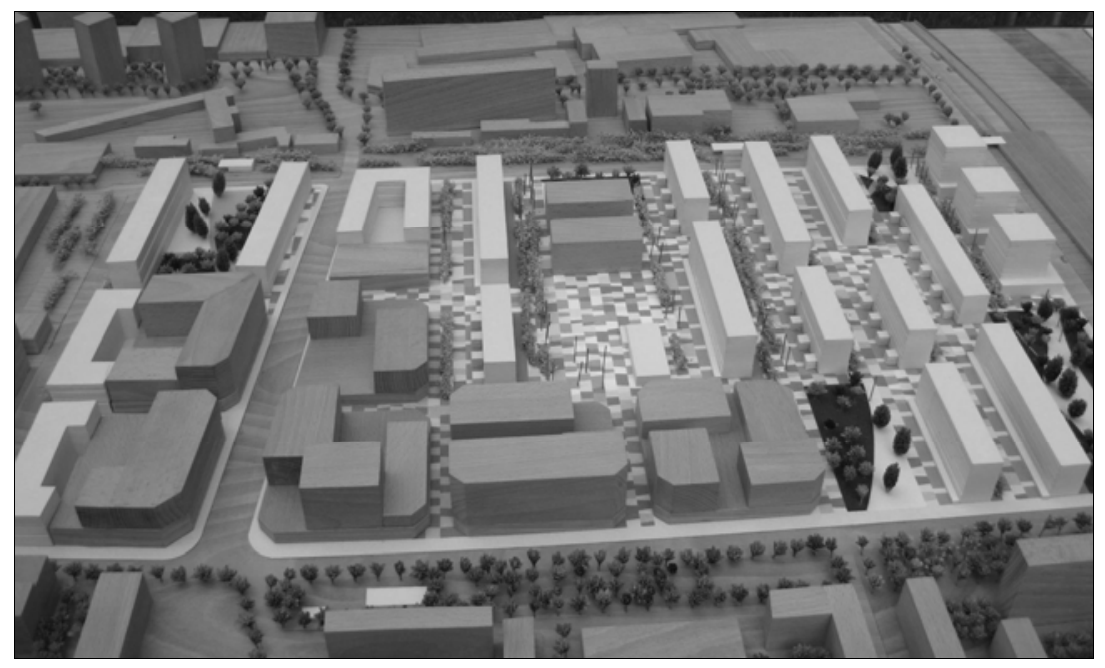

I MAGEN 4: Maqueta del Plan de remodelación del barrio. Foto Martha Pelayo, 2010.

\section{Una gente de fuera}

El derribo de las casas baratas llega a tocar precisamente la supervivencia del elemento unificador y estructurante de la comunidad de vecinos: las casas. La organización social de la cual hemos descrito algunos elementos, existe en cuanto 


\section{perifèria}

Número 12, junio 2010

www. periferia. name

homólogo estructural de la organización espacial del barrio de Casas Baratas. Poner en peligro este último elemento implica desarticular las funciones sociales de las cuales es portador.

Esta es la razón por la cual ninguna etnotécnica ha sabido sostener el conflicto entre "favorables" y "contrarios" al Plan: porque el elemento en juego son las casas mismas. En el 2003, hubo dos desagradables episodios en que los enfrentamientos entre los dos grupos llegaron a las manos ${ }^{35}$; a partir de entonces, las dos partes no se hablan más, dejando el problema en manos de los abogados y de los tribunales. En un espacio tan cargado de símbolos y de relaciones, dejar de hablarse tiene muchas más consecuencias de lo que podríamos imaginar. "Hemos sido casi familia, y ahora ni nos saludamos cuando nos vemos por la calle". La brecha social se fue ampliando como una epidemia, precipitando cada vez más familias en la incomunicación y en la hostilidad.

El 19 de octubre del 2007, un contingente del cuerpo de antidisturbios de la Guardia Urbana hizo irrupción en las viviendas de cuatro familias "de toda la vida" de las casas baratas, tirando abajo con la fuerza las puertas de los vecinos, incluso de dos personas mayores de 70 años, y obligándoles a dejar sus casas. La orden de desahucio había venido acompañada de una ambigua comunicación del Departamento de Urbanismo, en la cual se hacía referencia a un supuesto "error informático" por el cual el alquiler de estas familias, hasta ese momento al corriente de pago, se había cobrado indebidamente, por haberse cortado de forma unilateral sus contratos ocho meses antes, "debido a la aprobación del Plan urbanístico". El consejo que los vecinos habían recibido de sus abogados fue de ignorar la comunicación, ya que el caso estaba en manos del Tribunal de Contencioso Administrativo, que había pedido medidas cautelares de protección de las casas;

\footnotetext{
35 Con ocasión de la consulta sobre el Plan, unos miembros de la Asociación de Vecinos rompieron las pancartas con que los Avis del Barri pedían votar "no"; pocos meses después, en un Pleno de Distrito en La Sagrera, un miembro de los Avis del Barri pegó un puñetazo en la espalda de un miembro de la Asociación.
} 


\section{perifèria}

Número 12, junio 2010

www.periferia. name

además, la rescisión de los contratos no podía realizarse de esta forma, sino a través de una negociación, o por falta de pago ${ }^{36}$.

Después del desahucio, una violenta carga policial provocó varios heridos, incluso entre habitantes ancianos de las casas baratas que habían venido a mirar y a ofrecer ayuda a sus vecinos. La carga fue retratada en varios medios de comunicación, incluso nacionales ${ }^{37}$; al haber sido herido un periodista, el Colegio de periodistas pidió una inspección, que nunca llegó a hacerse. Las familias desahuciadas, después de algunas noches de hotel, fueron realojadas en los nuevos pisos, desde donde continúan a la espera de la resolución del Contencioso sobre su derecho a permanecer en sus casas.

Alrededor de la brecha entre "favorables" y "contrarios", la irrupción de la violencia policial se sublimó y externalizó: las dos partes se acusaron recíprocamente de "haber traído a gente de fuera" para provocar el malestar. El lado de los "contrarios" acusa a la Asociación de Vecinos y a sus simpatizantes de "haber traído a la policía", es decir avisado los antidisturbios para que realizaran el desahucio; el lado de los "favorables" reitera la acusación, a los Avis del Barri y a los vecinos desahuciados, de "haber traído a okupas" o a "gente de otros barrios" para "armar follón".

Sin embargo, entre esta "gente de fuera" están todos los que durante estos años se han interesado en el barrio: estudiantes, fotógrafos, arquitectos, antropólogos ${ }^{38}$, hasta los mismos organizadores del Concurso de ideas. Entre 2006 y 2007, un grupo independiente de técnicos de varias disciplinas, ya implicados en diferentes procesos vecinales, trabajaron durante un año en el análisis de los llamados "procesos participativos" puestos en marcha por el Ayuntamiento, en la reforma de diferentes zonas de Barcelona. Las conclusiones, publicadas bajo el título A

\footnotetext{
${ }^{36}$ Una de las razones de esta decisión fue que la aprobación del Plan afectaba a la totalidad de las 784 casas baratas, que por lo tanto hubieran tenido que colectivamente dejar de pagar los alquileres.

37 "Incidentes en Barcelona por el desalojo de cuatro familias". El País, 20/10/2007, p.30.

38 Desde los arquitectos de la ETSAB que organizaron en 2007 el taller "Arquitectura y participación", evaluando el estado de las Casas Baratas; hasta los que en 2009 organizaron el workshop "Publiciutat" en el MACBA (http://publiciutat.blogspot.com, consultado el 27/4/2010).
} 


\section{perifèria}

Número 12, junio 2010

www.periferia. name

Barcelona la Participació canta ${ }^{39}$, fueron que la palabra participación escondía, en la gran mayoría de casos, unos procesos dirigidos desde arriba. La voluntad del Ayuntamiento de esconder la verticalidad de sus decisiones con una repetición obsesiva de los eslóganes participativos, en folletos y publicaciones, "canta mucho", es decir delata la mala conciencia institucional y la falta de consenso ciudadano. ¡El mismo grupo decidió añadir al dossier incluso un Manual de defensa contra los "procesos participativos" de la administración!

A otro nivel, otra asociación, esta vez internacional, fue interesándose por el problema de las casas baratas de Bon Pastor. La Alianza Internacional de Habitantes (International Alliance of Inhabitants, o IAI), red mundial en defensa de los derechos de los inquilinos, entró en alerta con los desalojos forzosos de Bon Pastor en octubre 2007. Después de haber estudiado el caso, siempre a partir de la demanda de los Avis del Barri, pero también a través de sus canales de comunicación en Barcelona, consideró oportuno intervenir, no para apoyar una de las partes en conflicto, sino para elaborar una estrategia que pudiera ayudar a cohesionar de nuevo la comunidad. De esta convergencia de fuerzas nació el Concurso Repensar Bonpastor.

\footnotetext{
39 La referencia es a un eslógan empleado en ese momento por el Ayuntamiento en una "fiesta de la participación ciudadana": A Barcelona la participació sona (es decir, toca música). El dossier se encuentra en http://straddle3. net/participacio/ (consultado: 27/4/2010).
} 


\section{perifèria}

Número 12, junio 2010

\section{www. periferia. name}

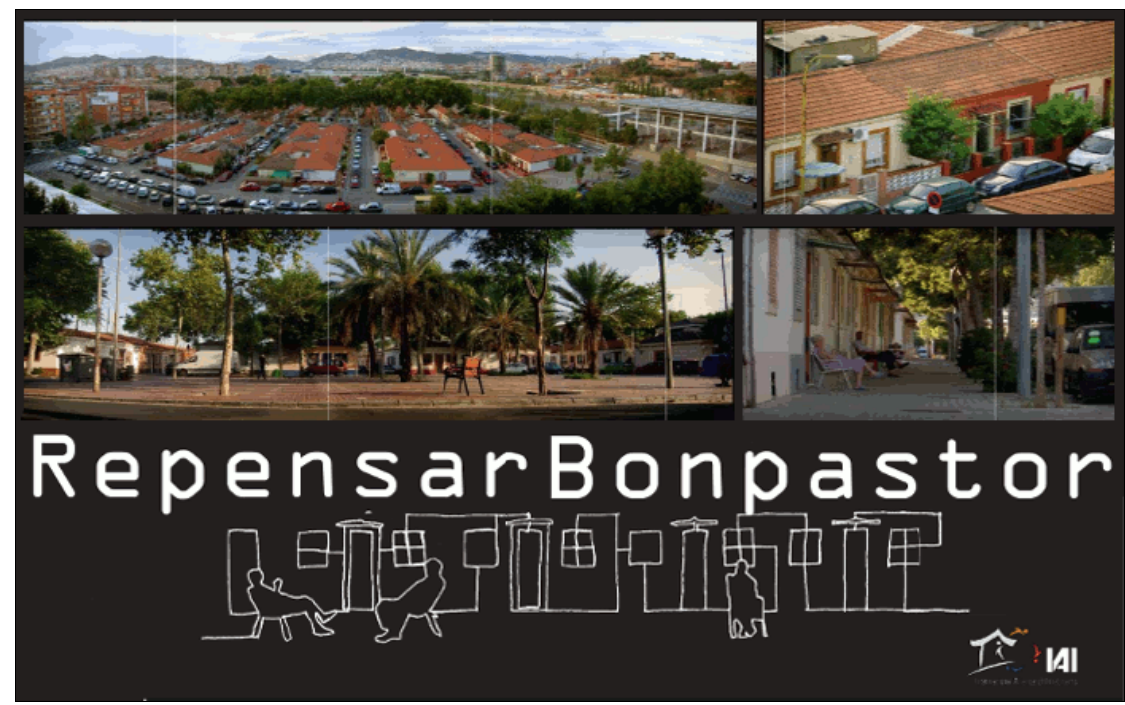

I MAGEN 5: Logo de presentación del Concurso de ideas.

\section{El concurso de ideas}

Ciento cincuenta y cuatro grupos de todo el mundo se inscribieron en el concurso, a través de su página web repensarbonpastor.wordpress.org. Las propuestas entregadas finalmente fueron cuarenta y cinco, en formato de láminas DIN-A1. Los criterios que se emplearon para valorar las propuestas fueron: el respeto del patrimonio histórico y social del barrio, la participación activa de los vecinos en el proceso de decisión sobre el barrio, la interdisciplinaridad de la propuesta, y la viabilidad de la solución propuesta. El jurado se reunió en Bon Pastor a principios de marzo; lo conformaba un grupo de expertos locales e internacionales ${ }^{40}$, que durante tres días de debate seleccionaron veintidós propuestas; entre ellas, decidieron premiar a cuatro, y conceder una mención especial a una quinta ${ }^{41}$. A pesar de la distancia, incluso geográfica, que implica que la mayoría de las

\footnotetext{
40 Teresa Tapada, antropóloga, Universitat Autónoma de Barcelona; José Luís Oyón, arquitecto, Escuela Técnica de Arquitectura del Vallés; Manuel Delgado, antropólogo, Universidad de Barcelona; Raquel Fosalba, activista autogestionaria, cooperativas de vivienda de Montevideo, Uruguay, residente en Barcelona; Micheal Herzfeld, antropólogo, Universidad de Harvard; Yves Cabannes, London University College, miembro del grupo consultor sobre derechos de la vivienda de las Naciones Unidas (United Nations Advisory Group on Forced Evictions, o UN-AGFE).

${ }^{41}$ Todas las propuestas pueden consultarse en http://repensarbonpastor.wordpress.com
} 


\section{perifèria}

Número 12, junio 2010

www. periferia. name

propuestas se hayan elaborado sin un conocimiento profundo del barrio, de su estructura y de sus dinámicas, prácticamente de cada una de ellas se pueden extraer elementos interesantes. Arquitectos, antropólogos y otros profesionales y estudiantes, han tenido que entenderse y trabajar juntos, alrededor de una necesidad concreta expresada por un grupo de vecinos. Aunque los participantes supieran que la posibilidad de que sus propuestas vayan a ser implementadas es prácticamente nula (dada la voluntad del Patronato de seguir con la Remodelación actual), la gran cantidad de propuestas presentadas nos impresiona y nos obliga a reflexionar.

Nos encontramos ahora - y es este el verdadero resultado del concurso - con una gran cantidad de profesionales, tanto locales como internacionales, interesados en profundizar el estudio de la situación para seguir contribuyendo en la búsqueda de soluciones. Algunos proponen un análisis de la posible ampliación y rehabilitación de las Casas Baratas; otros, estudian la aplicación de una metodología participativa que permitiría un trabajo compartido entre las partes enfrentadas; otros aconsejan la creación de cooperativas de habitantes, para la gestión de una transformación urbanística que no implique desalojos, y que facilite el acceso a la vivienda para todos.

No ha sido fácil, para toda esta "gente de fuera", atravesar las barreras lingüísticas, culturales, económicas, creadas alrededor del barrio, tanto desde dentro (por autodefensa) como desde fuera (por estigma). Tampoco ha sido fácil, para los habitantes del barrio, gestionar las acusaciones de "traer" a los forasteros: la presencia de extranjeros (en el concurso han participado argentinos, alemanes, mexicanos, italianos, griegos...) puede despertar una xenofobia territorial, y la presencia de personas con estudios genera a menudo la esquismogénesis de clase. El chafarderío entre los vecinos es un elemento estructurante de todas las relaciones en las Casas Baratas, verdadero hecho social total. Toda la proxémica en el espacio público - las miradas, los saludos, incluso la decisión de circular por una calle u otra - se rige por normas que los forasteros ignoran y que incumplen sistemáticamente; los habitantes de las casas lo saben bien, y tienen que controlar constantemente los mensajes que circulan alrededor de ellos. 


\section{perifèria}

Número 12, junio 2010

www. periferia. name

A menudo, los habitantes del barrio - entre los cuales algunos están ahora familiarizándose con las propuestas y estudiando la manera para poner en marcha una alternativa - no entienden la motivación que ha llevado a esta "gente de fuera" a interesarse por el problema del barrio, y a enfrentarse con estas dificultades, sin ninguna retribución aparente. La clave está en la afirmación del geógrafo barcelonés Horacio Capel: "el uso del calificativo obsoleto es desmesurado. Se utiliza para tomar decisiones injustificadas ${ }^{42 "}$. Todos los que pudimos conocer desde fuera el barrio de Casas Baratas de Bon Pastor nos dimos cuenta de la magnitud de esta desmesura. Un barrio destinado al derribo, que la propaganda municipal presenta como indigno y degradado, esconde en su interior unas calidades que podrían hacer de él un modelo de ciudad para el futuro.

Cada uno según su interés y formación, las personas que nos interesamos por este barrio, desde la Plataforma Vecinal en 2004 hasta la organización del Concurso en 2009, hemos encontrado en él aspectos que son potenciales antídotos al urbanismo y a la homogeneización cultural de nuestros tiempos. Los arquitectos han visto en las casas la posibilidad de una modernización más sostenible, duradera y adaptable a las necesidades de las clases populares, respeto a la masificación de la vivienda popular. Los urbanistas han encontrado una estructura residencial que recuerda la ciudad jardín ideal, pero de la cual los habitantes se han apropiado y que ha llegado hasta ahora. Los antropólogos hemos encontrado en las casas baratas estructuras autónomas de resolución de conflictos, incluso capaces de equilibrar las tensiones étnicas.

¿Existe una manera en la cual el barrio pueda llegar al futuro, sin renunciar a su patrimonio histórico y cultural, sin expulsar a una parte de la población para dar más espacio a otra, pero sin caer otra vez en el abandono y el olvido? Una transformación tan ambiciosa, evidentemente, no pueden gestionarla ni las

\footnotetext{
${ }^{42}$ La veu del Carrer n.87, noviembre-diciembre 2004.
} 


\section{perifèria}

Número 12, junio 2010

www. periferia. name

instituciones ni sus contrapartes establecidas en el barrio, vistos los conflictos generados por el proyecto actual. Como se lee en la resolución del Jurado ${ }^{43}$,

[...] sólo con la elaboración previa de una diagnosis precisa que profundice en la composición social del barrio, en el cual se reconocen las diferencias demográficas, de origen y etnia, de redes familiares y de vecindario, y también los sistemas de trasmisión de la propiedad - será posible elaborar una propuesta de proyecto que sea consistente, real y seria, y que pueda permitir el desarrollo futuro del barrio sin causar una fractura social. La fase de diagnosis tiene que basarse en una investigación de campo desde las ciencias sociales que cuente con las herramientas calitativas necesarias para este propósito, si es posible incluyendo las que ofrecen los campos de la antropología social y cultural. La fase de elaboración del proyecto, y el posterior proceso de implementación, tienen que contar con la colaboración de los vecinos, cuya mejora en las condiciones de vida es el objetivo final de la intervención.

Los motores de la transformación sin duda tienen que ser los vecinos; quizás organizados en algún nuevo tipo de estructura, que no despierte los rencores de ninguna de las partes enfrentadas, y que estimule, en vez de desincentivar, la participación y la expresión de los deseos de la población. Los antropólogos podemos desarrollar aquí un papel parecido al que tuvieron algunos etnógrafos en la época de la descolonización: construir un dispositivo que restituya su valor a la historia, la cultura y los estilos de vida propios de la comunidad ${ }^{44}$, para contrastar la interiorización del discurso del poder, que promueve su disgregación y homologación ${ }^{45}$. Para una población acostumbrada desde hace demasiadas décadas a que sus necesidades sean sistemáticamente ignoradas por las autoridades, nuestra intervención podría potenciar la confianza de la comunidad en sí misma, la

\footnotetext{
43 Attached document to the Final record of the Jury decision for the "ideas competition for the participative and zero evictions renewal of a popular neighborhood of Barcelona". International Alliance of Inhabitants, 16 marzo 2010. Traducción propia.

${ }^{44}$ Hay antecedentes de este enfoque: Oyón 1988, Gavaldà 2007.

45 Un discurso de poder es, según Barthes, un discurso que engendra la conciencia de una falta. No estamos lejos del que se ha definido disease mongering o promoción de la enfermedad (Payne, 1992).
} 


\section{perifèria}

Número 12, junio 2010

www.periferia. name

cohesión y la autoestima colectiva, únicos elementos que permitirían un proceso vecinal realmente autogestionado.

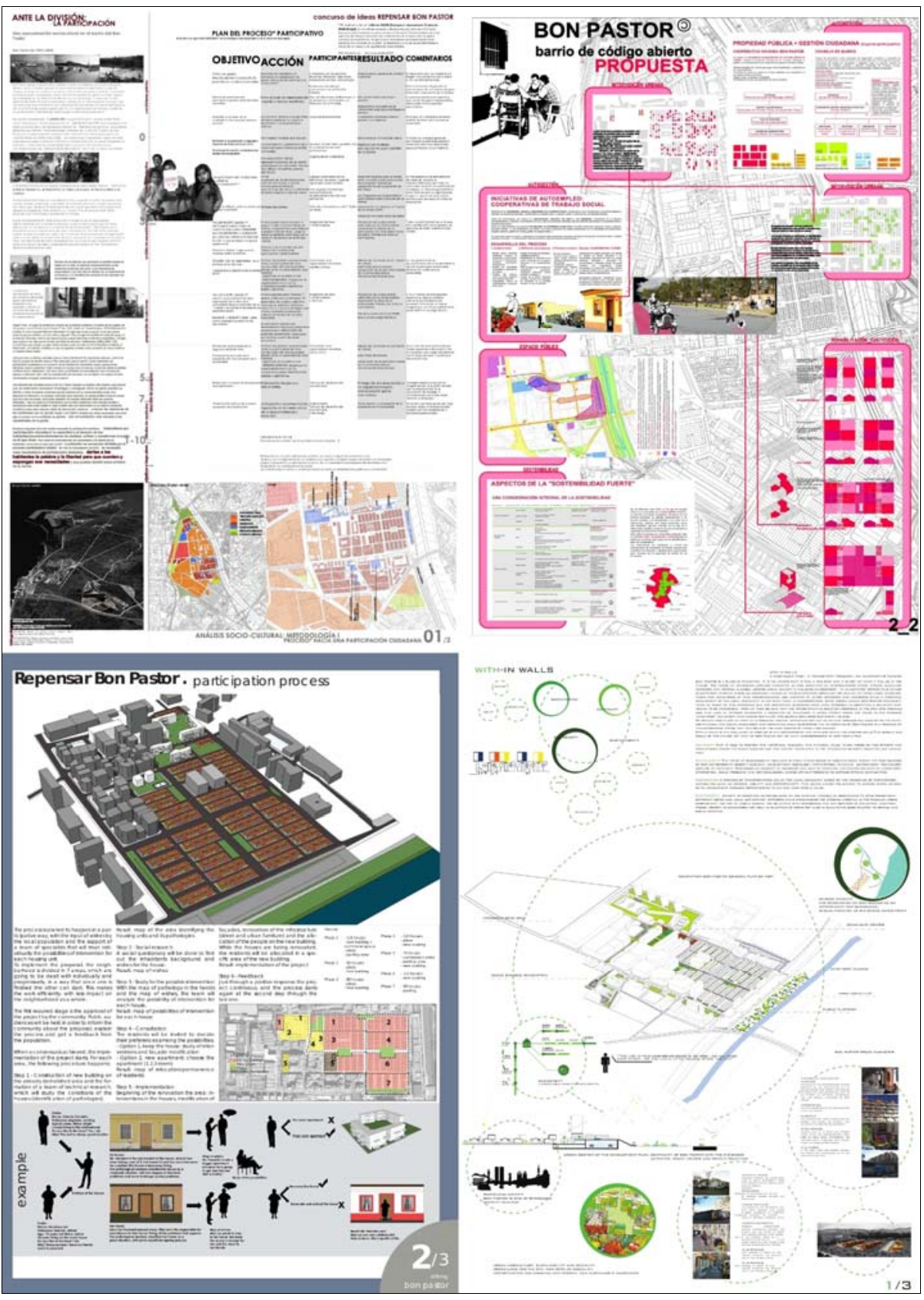




\section{perifèria}

Número 12, junio 2010

www. periferia. name

I MAGEN 6: Una lámina de cada una de las cuatro propuestas ganadoras Ante la división la participación, de Naomi Ferguson y Afroditi Karagiorgi; Bon Pastor, barrio de código abierto, de Marian Simón, Nerea Morán, Cristina Fernández, Gorka Ascasíbar y Quim Vilar; Refining Bon Pastor, de Karin Fernanda Schwambach, Susan Eipper y Fernando Campo Medina; With-in Walls, de Barbara Dovarch, Stefano Grigoletto, Sara Incerti, Gynna Myllan, Marta Pietroboni, Luca Serra y Pietro Pusceddu

\section{Bibliografía}

Ajuntament de Barcelona (2003) De les cases barates als grans polígons. El Patronat Municipal de l'Habitatge entre 1929 i 1979. Barcelona: Ajuntament de Barcelona.

Amelang, J. (2007) "Comparing cities: a Barcelona Model?". Urban History, n.34, pp. 173-189.

Blanco, I. (2009) "Does a Barcelona Model really exist? Territories and actors in the process of urban transformation". Local Government Studies, vol.35, issue 3, junio 2009, pp. 355-369.

Brunello, P. (ed., 1996), L'urbanistica del disprezzo. Campi rom e società italiana, Roma, Manifesto Libri.

Capel, H. (2005) El modelo Barcelona. Un examen crítico. Barcelona: Ediciones del Serbal.

Checa, M. (2002) “Els inicis de la colonització urbana a la dreta del Besòs (19061930)" in Àgora. Revista d'història de Santa Coloma de Gramenet, n. 7, marzo, pp. 89-113.

Checa M., Travé, C. (2007) Bon Pastor, història d'un barri. Barcelona: Ajuntament de Barcelona, Direcció de Participació Ciutadana Districte de Sant Andreu, Pla de Futur de Bon Pastor.

Cortinas, J. (1992) Memòries de Mossén Joan Cortinas. Una vida de servei als altres. Santa Coloma de Gramenet: Ajuntament de Santa Coloma de Gramenet.

Dattwyler, R.D. (2000) "La política de Casas Baratas a principios de siglo XX. El caso chileno" Scripta Nova. Revista Electrónica de Geografía y Ciencias Sociales, n. 


\section{perifèria}

Número 12, junio 2010

www. periferia. name

55, enero 2000.

Delgado, M. (ed, 2003) Carrer, festa i revolta. Els usos simbòlics de l'espai públic a Barcelona (1951-2000). Barcelona, Generalitat de Catalunya.

Delgado, M. (2007) La ciudad mentirosa. Fraude y miseria del "modelo Barcelona". Madrid: Los libros de la Catarata.

Espinosa, F. (2005) El fenómeno revisionista o los fantasmas de la derecha española. Badajoz: Los libros del Oeste.

Fabre, J. y Huertas Clavería, J.J., Tots els barris de Barcelona. Barcelona: Edicions 62.

Fermigier, A. (1991) La bataille de Paris. Des Halles à la Pyramide, chroniques d'urbanisme. Paris: Gallimard.

Gallardo Romero, J.J . (2000) Los orígenes del movimiento obrero en Santa Coloma de Gramenet. El anarcosindicalismo (1932-1936). Santa Coloma de Gramenet: Grupo de Historia J osé Berruezo.

Gavaldà, J. (2007) “El Plan de Ordenación Urbanística Municipal de la ciudad de Tarragona de 2007 y su incidencia sobre el conjunto arquitectónico de las Casas Baratas". Biblio 3W Revista Bibliográfica de Geografía y Ciencias Sociales, Vol.XII, n. 757.

Herzfeld, M. (2009) Evicted from Eternity. The Restructuring of Modern Rome. Chicago: The University of Chicago Press.

Márquez Rodriguez, J.M. (2000) “Estructura socioeconómica de Barón de Viver en 1936" Agora. Revista de Historia de Santa Coloma de Gramenet n.8, marzo.

Miñarro, A., Morandi, T. (2009) “Trauma psíquic i transmissió", Quaderns de Salut Mental, n.5.

Ontiveros, R. (1992), “A I'altra banda del Besós. Els terrenys segregats a Santa Coloma el 1945". Puig Castellar, n.3-4, junio, pag 62-73.

Ortego Gil, P. (2006) Las casas baratas. Madrid: I ustel. 


\section{perifèria}

Número 12, junio 2010

www. periferia. name

Oyón, J.L. et al. (2005) El cinturón rojinegro. Radicalismo cenetista y obrerismo en la periferia de Barcelona. Barcelona: Ediciones Carena.

Oyón, J.L. (1998) "La conservación de la vivienda popular en las periferias urbanas.

El caso de Barcelona y la Colonia Castells". Scripta Nova. Revista Electrónica de Geografía y Ciencias sociales, n. 21.

Pasolini, P.P. (1992) Dialoghi. Roma: Editori Riuniti.

Passerini, L. (1998) "Work ideology and consensus under Italian fascism" en Perks, R., Thomson, A. The Oral History Reader. London: Routledge, pag.53-62.

Patronato Municipal de la Vivienda (1999). Barcelona. Les Cases Barates. Barcelona: Ajuntament de Barcelona.

Payne, L. (1992) Disease-Mongers: How Doctors, Drug Companies, and Insurers Are Making You Feel Sick. New York: Wiley and Sons

Raventós, F. (2000) La col·laboració público-privada. Model Barcelona, Quaderns de Gestió n. 8. Barcelona: AULA Barcelona.

Ruíz-Vargas, J.M. (2006) "Trauma y memoria de la Guerra Civil y de la dictadura franquista" Hispania Nova. Revista de historia contemporánea, n.6, pp. 299-336.

San Román, T. (1997) La diferencia inquietante. Viejas y nuevas estrategias culturales de los gitanos. Madrid: Siglo XXI.

Turner, V. (1967) The forest of symbols. Aspects of Ndembu ritual. Ithaca (NY): Cornell University Press.

UTE (Unió Temporal d'Escribes, 2004) Barcelona marca registrada. Un model per desarmar. Barcelona: Virus Editorial. 